\title{
OFERTA DO TRABALHO NA CHINA: O SISTEMA HUKOU E O PARADOXO DA ESCASSEZ
}

\section{Labor Supply In China: The Hukou System And The Paradox Of Scarcity}

\author{
Mario Henrique Ogasavara \\ Universidade de Fortaleza - UNIFOR \\ marioga@unifor.br
}

Gilmar Masiero

Faculdade de Economia e Administração - FEA/USP gilmarmasiero@gmail.com

Submissão: 19/09/2012

Aprovação: 03/04/2013

\begin{abstract}
Resumo
Para muitos estudiosos da questão do trabalho na China, o fato do país possuir grande oferta de mão de obra a baixos custos continuará sendo um fator determinante da maior competitividade e crescimento das empresas chinesas vis a vis suas similares internacionais. Este artigo busca qualificar e aprofundar o debate sobre a contribuição do fator trabalho à competitividade das empresas chinesas. Com base em extensa revisão de literatura e entrevistas com executivos de algumas das mais representativas empresas dos setores básicos das indústrias chinesas o artigo discute o sistema hukou que possibilitou significativos ganhos de competitividade das empresas chinesas ao longo dos últimos trinta anos. Descreve a política de controle de natalidade que tem grande relação com as questões de trabalho migrante e a baixa remuneração da força de trabalho chinesa e considera, de um lado, o excedente da oferta de trabalho, e de outro lado, a escassez de mão de obra na China discutindo se o país alcançou ou não o 'Lewis Turning Point', que é o referencial teórico desse paradoxo. Alguns depoimentos de executivos de grandes empresas chinesas sobre questões do trabalho são descritos juntamente com as considerações finais do artigo.
\end{abstract}

Palavras-chaves: hukou system, trabalho, China, Lewis Turning Point 


\begin{abstract}
For many scholars of labor markets in China, the large supply of low-cost labor is a key determinant of the competitiveness and growth of Chinese enterprises vis-à-vis its international competitors. Yet, the scholarly literature also documents that there are acute shortages of labor in key sectors of the Chinese economy with important effects on wages. This article seeks to reconcile the complex dynamics of labor market dynamics in China by qualifying and deepening the debate on the contribution of labor supply to the competitiveness of Chinese enterprises. Based on both primary and secondary data, the article reviews the most important supply-side determinants for Chinese competiveness including the hukou system and the birth control policies. In addition to assessing the contribution of these factors, it also considers the evidence in favor of a shortage of manpower in key sectors of the Chinese economy. In doing so, it focuses on assessing whether or not the country has reached the "Lewis Turning Point.'
\end{abstract}

Keywords: hukou system, labor, China, Lewis Turning Point 


\section{Introdução}

Em setores dinâmicos da economia chinesa como o metal-mecânico, eletroeletrônico e químico, a importância dos custos do trabalho na competitividade das empresas é significativa. Para muitos analistas e acadêmicos estudiosos da questão do trabalho na China, o fato do país possuir grande oferta de mão de obra a baixos custos continuará sendo um fator determinante da maior competitividade e crescimento das empresas chinesas vis a vis suas similares internacionais.

A existência de uma força de trabalho abundante é condição fundamental para o processo produtivo de um país, sendo importante fator da formulação de políticas de emprego. De acordo com as informações do China Labour Statistical Yearbook (2010), a China, como país mais populoso do planeta (1,33 bilhão de pessoas em 2009), também conta com uma força de trabalho gigantesca de aproximadamente 800 milhões de pessoas, sendo $60 \%$ dela, localizada na área rural. Estes números impressionam devido à sua magnitude. Apenas a população empregada na área urbana é superior a toda população dos Estados Unidos (307 milhões em 2009, segundo dados do Banco Mundial) e o incremento de chineses empregados a cada ano (8 milhões, no período 2008-2009) é maior que toda a força de trabalho do Chile (7,5 milhões) ou de outros países de pequena magnitude populacional. A maior parte dessa força de trabalho chinesa está localizada na região costeira, dado que o oeste e noroeste do território são montanhosos e desérticos.

Em 1978, antes do início das reformas econômicas na China, a área rural correspondia a 76\% do emprego no país, demonstrando ser uma típica estrutura de economia agrícola (CAI; WANG, 2010). Como resultado das reformas econômicas, esta participação caiu para $60 \%$ em 2009. Esta diferença de $16 \%$, entretanto, não é suficiente para caracterizar o ritmo do crescimento econômico, observadas as mudanças estruturais ocorridas no país e sua rápida urbanização ao longo das últimas três décadas, em que a economia chinesa se expandiu entre 1980 e 2009 a uma taxa média de 9,7\% ao ano. Faz-se necessário verificar peculiaridades desse processo e algumas delas o são nos demais itens subsequentes deste artigo. 


\section{Trabalhadores migrantes rurais}

A oferta de força de trabalho abundante aliada a um baixo custo de mão de obra, particularmente proveniente da área rural para o setor industrial, vem sendo considerada por Chan (2008) como um dos pontos chaves para o grande crescimento econômico da China nestes últimos trinta anos e pelo sucesso do Made in China. Os trabalhadores migrantes rurais tornaram-se a espinha dorsal da indústria chinesa em meados dos anos noventa. No início do Século XXI a grande maioria da força de trabalho (70-80\%) em cidades com foco para a exportação, como Shenzen e Dongguan, era composta de trabalhadores migrantes (LIANG, 1999; CHAN, 2007). Mesmo em cidades do interior, como em Wuan, trabalhadores migrantes representavam $43 \%$ do emprego no ano de 2000, enquanto que em cidades de maior porte como Pequim e Xangai, Chan (2009) estimou que os trabalhadores rurais contribuíram com cerca de 30\% do Produto Interno Bruto dessas localidades em 2007.

Os números oficiais desses trabalhadores migrantes ainda são obscuros, pois a migração chinesa é complexa considerando arranjos institucionais, sistema populacional e gestão de migrantes. Esta dificuldade de mensurar pessoas fez com que pesquisadores das Nações Unidas denominassem esta "população flutuante" de "estatisticamente invisível" (UNITED NATIONS DEVELOPMENT PROGRAMME, 1999), pois, segundo Roberts (2002) é muito difícil de serem identificados nos dados estatísticos. A estimativa é que esses trabalhadores migrantes correspondiam a 145 milhões de pessoas em 2009 (CHAN, 2010b).

Para analisar a questão da migração interna na China, primeiramente deve-se compreender melhor o sistema hukou e sua relação com a migração. Este sistema refere-se à permissão de residência na China iniciado nos anos cinquenta, quando tal registro tinha de ser formalmente requisitado. Nele, os indivíduos foram categorizados como trabalhadores 'rurais' ou 'urbanos'. De acordo com Wu (1994), com uma enorme população de trabalhadores rurais pobres, o sistema hukou limitou a migração em massa da área rural para as cidades.

Embora este sistema chinês de controlar e regular movimentos internos de seus cidadãos seja frequentemente considerado por Goldstein e Goldstein (1991) como único da China, Zhu (2003) revelam que sistemas similares existiram em outros países, como o hokhau no Vietnã e o hoju na Coreia do Norte. De fato, todos estes sistemas de controle de migração têm origem comum, inclusive o chinês, na propiska (passaporte interno) utilizada nas ex-Repúblicas Soviéticas (ZASLAVSKY; LURYI, 1979; DUTTON, 1992; MATHEWS, 1993).

No caso chinês, o sistema de registro populacional e residencial possui uma longa história tendo sido utilizado desde a Dinastia Xia (2100 a.C. - 1600 a.C). De acordo com Wang (2006), em certas ocasiões, o sistema foi empregado para controlar grupos populacionais, particularmente durante períodos de conflitos ou guerras. Contudo, em tempos de paz, esse sistema, nunca funcionou como controle social e econômico até 1949. Segundo Alexander e Chan (2004) e Naughton (2007) o estabelecimento de uma nova versão hukou durante os anos cinquenta foi resultado da implementação de um sistema econômico que demandou meticuloso planejamento e controle de toda a sociedade, baseado em uma estratégia de industrialização 'Big Push', de desigualdade de trocas entre a indústria e a agricultura. Como 
em outros países comunistas, a industrialização 'Big Push', também conhecida como a 'estratégia tradicional de desenvolvimento socialista', foi notória ao criar uma grande disparidade entre os setores urbano-industrial e rural-agrícola.

Ao implementar tal estratégia, o Estado controla os recursos no setor rural para acumulação de capital através do processo conhecido como 'scissors prices' (CHAN, 1994). Na visão de Yang e Fang (2003) para o sucesso da implementação desse processo, o Estado precisa exercer coerção usando simultaneamente três mecanismos: a) a aquisição compulsória e monopólio das vendas da produção rural; b) o sistema rural coletivo; e c) o sistema hukou que controla a mobilidade da população. O primeiro mecanismo foi utilizado para gerar trocas inter-setoriais desiguais, enquanto o segundo e terceiro foram empregados para assegurar a implementação destas trocas.

Ao adotar esta estratégia de industrialização nos anos cinquenta, houve na China um grande número de trabalhadores rurais que começou a migrar da zona rural para as cidades. Embora a liberdade de migração e residência tenha sido introduzida temporariamente na 'constituição' de 1949 e preservada na primeira Constituição de 1954, o Estado tomou medidas para impor a checagem de documentação de viagens e outros controles administrativos em diversos locais, como nas estações de trem, entre 1955 a 1957. Estes migrantes foram chamados de forma pejorativa como "blind blows" nos documentos oficiais, como se eles fossem grandes causadores de problemas. Posteriormente, ficou claro que um modo mais sistemático e coercivo seria necessário para prevenir ou no mínimo regular tal fluxo indesejável' de migração rural-urbano. Foi então que, segundo Chan (2009), o hukou representou um componente importante desse sistema de controle.

O sistema hukou foi modernamente estabelecido em 1951, para registrar a residência da população urbana e identificar qualquer elemento anti-governo. O Ministério de Segurança Pública (MSP) chinês publicou o Regulamento Provisório de Administração do Hukou Urbano e com o primeiro censo chinês, realizado em 1953, foram criados os registros necessários para o hukou rural. Mallee (1995) aponta que o sistema foi posteriormente estendido em 1955 para cobrir tanto a população rural como a urbana. Em 1958, foi promulgada uma lei mais abrangente para o controle dos fluxos populacionais na China, o Regulamento sobre Registro de Residência (Hukou) da República Popular da China.

Para Wu (1994), os chineses são divididos em duas categorias: moradores urbanos e rurais. Porém, na prática, existem quatro grupos, urbano, rural, agrícola e não-agrícola, e a relação entre os quatro não são diretas como poderia parecer a princípio (rural-agrícola e urbano-nãoagrícola). A divisão entre o que é rural e urbano na China é feita segundo um critério de localização administrativa e a distinção entre agrícola e não-agrícola segue critérios relacionados com as atividades dos trabalhadores chineses.

Mesmo nos dias atuais, a regulamentação de 1958 representa a única legislação nacional de imigração e residência promulgada pelo Congresso Nacional da China que ainda se encontra em vigor em sua plenitude, apesar de sua execução ter sido flexibilizada em inúmeras ocasiões. Segundo Zhu (2003) esta regulamentação exigiu que toda a imigração interna ficasse sujeita à aprovação das autoridades locais do destino, ou seja, tirou o direito básico dos 
cidadãos chineses em ter a liberdade para ir e vir e de fixar residência, presente apenas nos 26 primeiros anos da Constituição da República da China.

\subsection{Relacionamento do sistema hukou com a industrialização}

No intuito de implantar o programa de industrialização chinês, dois subsistemas (economia e sociedade) foram criados pelo Estado com algumas pré-condições. O setor industrial, geralmente em áreas urbanas, foi designado como 'prioritário' para a economia do país, sendo, desta forma, estatizado. Isto significa que este setor recebeu forte apoio e proteção do Estado e foi colocado sob uma administração governamental bem restrita. Benefícios sociais e subsídios básicos foram concedidos aos trabalhadores urbanos e suas famílias no intuito de manter a estabilidade social e política desse subsistema. Mesmo sendo básicos, os benefícios eram caros e somente poderiam ser oferecidos a um pequeno setor 'prioritário' (15-16\% da população em 1955), que foi mantido neste nível até 1978 (CHAN, 1992; CHENG; SELDEN, 1994; WANG, 2005).

Outro subsistema denominado 'não-prioritário' (setor rural-agrícola) englobava o restante da população (85\%). Foi tratado como 'residual' sendo que sua função principal era de oferecer matéria-prima barata (incluindo alimentos como grãos), trabalho e capital para o setor urbanoindustrial. A população rural e sua produção foram coletivizadas para servir a tais funções, tendo sobre si um mecanismo de policiamento pelo Estado. A população rural, excluindo os benefícios e subsídios oferecidos pelo Estado, não tinha como requerer recursos nacionais e teria que se sustentar, exceto em tempos marcados por extrema dureza ou emergência. A principal tarefa era produzir alimentos e matérias-primas com preços (baixos) estabelecidos pelo Estado para sustentar o monopólio da indústria estatal.

Assim, ao imobilizar os agricultores, forçando-os a trabalhar sua terra, assegurando-lhes basicamente o consumo ao nível de subsistência e excluindo-os do acesso aos benefícios sociais sem a permissão para se mudar para as cidades, esse sistema, segundo Naughton (2007), criou duas diferentes sociedades: uma urbana e outra rural. Devido a esta imobilidade de natureza hereditária da classificação hukou, os agricultores tornaram-se de fato uma classe desfavorecida (CHAN, 2009). Existem, entretanto, algumas diferentes classificações de hukou detalhadas a seguir.

\subsection{Classificação do sistema hukou}

Chan e Buckingham (2008) informam que o hukou de cada cidadão chinês foi categorizado de acordo com duas classificações: uma baseada no tipo, dado que na China existem moradias familiares, que representam a maior parte da população e coletivas, e outra, na localização da residência. O tipo (leibie) ou natureza (xingzhi) do hukou é diferenciado em 'agrícola' (nongye) ou 'não-agrícola' (feinongye). Desde o início dos anos 60, esta classificação tem determinado os produtos, serviços e elegibilidade de benefícios concedidos pelo Estado. O status de hukou 'não-agrícola' segundo Cheng e Selden (1994) permite aos chineses o acesso à moradia, emprego, alimentos, educação, tratamento médico e outros benefícios oferecidos pelo Estado, sendo assim, considerados como detentores de hukou urbano.

O status do hukou mantém-se inalterado, não importando onde o indivíduo se estabeleceu ou para onde se mudou, a não ser que tenha passado por uma conversão formal. Por exemplo, 
uma pessoa com o status 'não-agrícola', independente de sua localização física (residindo em uma vila, pequena, média ou grande cidade, ou mesmo no campo), recebe automaticamente os benefícios básicos que são financiados pelo governo, fazendo com que este tipo de status 'não-agrícola' seja o mais desejado e procurado em todo país. Desta forma, o tipo de hukou é muito mais que um status social, sendo naturalmente uma consideração importante também no "mercado matrimonial". Segundo Wu (1994) e Chan (2009), isto se mantém inalterado até os dias de hoje.

Adicionalmente ao tipo de hukou, cada pessoa é categorizada de acordo com o lugar de registro de seu hukou (hukousuozaidi). Consiste no status oficial de residência individual 'permanente'. Em outras palavras, além do tipo de hukou, cada pessoa é diferenciada em função do local (bendi) em que realizou sua inscrição na respectiva unidade administrativa (como as cidades, vilas ou distritos). O registro regular de seu hukou local define o direito de cada pessoa em possuir habilidades e elegibilidade para desenvolver atividades em uma localidade específica.

Em virtude deste controle rígido de mobilidade durante a era Mao, quase todas as pessoas residiram (residência de facto) onde elas supostamente deveriam residir (residência de jure). Durante este período, o número de pessoas residindo em local diferente de sua residência de jure era bastante reduzido. De acordo com Chan (2008), mesmo no início dos anos 80, quando o tamanho deste grupo 'desviante' começou a crescer, o percentual ainda era insignificante, sendo de apenas por $0,6 \%$ de toda a população.

O movimento mais comum era da migração rural para regiões urbanas, mas era necessário obter a aprovação do Estado para converter o tipo de hukou 'agrícola' para 'não-agrícola' (processo denominado nongzhuanfei) e posteriormente a mudança do local do registro hukou (de uma vila específica para uma cidade em particular). Considerando estes dois passos de mudanças, o nongzhuanfei era de longe o processo mais crítico de conversão e muito difícil de obtenção. O processo de reclassificação do local de residência geralmente vinha junto com o nongzhuanfei. Na era Mao, conforme Chan (2009), o nongzhuanfei era concedido para as seguintes pessoas:

- Recrutadas como empregados permanentes pelas empresas estatais (zhaogong);

- Retiradas devido à expropriação de terras de interesse do Estado (zhengdi);

- Recrutadas para registro em instituições de ensino superior (zhaosheng);

- Promovidas para posições administrativas (zhaogan);

- Recolocadas por causa de problemas familiares (como mudança de cidade para viver ou cuidar dos pais doentes ou idosos);

- Entrar para o serviço militar (canjun);

- Consideradas como pertencentes a categorias especiais (ou beneficiárias da remuneração por erros políticos passados ou pessoas que tinham dificuldades pessoais ou profissionais em sua prestação de trabalho para o Estado);

Nota-se ainda que pessoas que cometiam certos crimes poderiam perder o status de hukou 'não-agrícola'. 


\section{A 'Era das Migrações'}

Apesar do rigor do sistema hukou, que foi contínuo ao longo dos últimos cinquenta anos, a migração começou a crescer na década de oitenta, resultando em uma situação relativamente oposta ao passado. Este período foi denominado como 'Era das Migrações' (LIANG, 1999), quando as pessoas mudam fisicamente dos locais onde habitualmente residiam para outras localidades, com ou sem a concessão dos direitos civis, políticos e sociais de cidadãos, como direito ao voto, educação pública, previdência social e outros benefícios. Na maioria dos países, a migração interna não é somente o movimento físico de pessoas (somente no caso de períodos curtos entre três a seis meses), mas também garante o direito de voto e acesso igualitário aos benefícios sociais do local de destino.

O que pode ser considerado único sobre a migração da China consiste em que estes dois aspectos da migração interna (movimento físico e cidadania) podem ser totalmente díspares, ou seja, a pessoa pode mudar para um novo local, porém será permanentemente excluída do acesso aos serviços e benefícios concedidos pelo governo. As pessoas que se mudam para uma nova localidade, mas não possuem a cidadania local (hukou) são consideradas como a população não-hukou, implicando não serem tidas como residentes de jure, embora sejam residentes de facto.

Certamente, a situação dos migrantes chineses sem cidadania não é única no contexto internacional. Muitos 'trabalhadores convidados' em um país estrangeiro, às vezes por anos sem cidadania local também se enquadram nesta categoria. Mas em tempos modernos, poucos países têm aplicado tal sistema a seus próprios cidadãos. Na China, este grupo é geralmente denominado de população 'flutuante' ou 'móvel' (renkouliudong), e seu número tem crescido rapidamente a partir de poucos milhões no início dos anos 80 para o nível atual de aproximadamente 145 milhões de pessoas (CHAN, 2010b), sendo o maior subgrupo constituído pelos trabalhadores migrantes rurais.

Um pequeno avanço ocorreu com a introdução de uma nova categoria hukou, denominada ‘hukou com auto-alimentação' em pequenas cidades em 1984 (CHAN; ZHANG, 1999). Esta nova categoria foi aplicada para enquadrar migrantes que mudavam para pequenas cidades, mas que não tinham conversão de hokous (nongzhuanfei), ou seja, o estado não tinha responsabilidade por qualquer benefício para estes novos migrantes. Uma oportunidade maior foi aberta para a migração no ano seguinte, com a política nacional de permitir residência temporária (SOLINGER, 1999). Era permitida a mudança e as pessoas podiam permanecer 'temporariamente' em um local diferente de onde eles foram registrados, incluindo grandes cidades, porém sem hukou local e todos os benefícios e direitos a ele atrelados. Esta nova política teve o intuito de acomodar a crescente demanda de trabalhadores com pouca qualificação para preencher as vagas e empregos urbanos criados por fábricas que foram implantadas na nova estratégia de industrialização voltada à exportação.

No início dos anos 1980, a China gradativamente implementou diversas reformas para repassar os poderes fiscais e administrativos para governos locais, incluindo mudanças na gestão do sistema hukou. Assim, governos locais tiveram maior controle para decidir sobre o 
hukou e não-hukou em suas respectivas jurisdições administrativas. No final dos anos noventa, alguns governos locais aboliram o nongzhuanfei, ou mais especificamente, eliminaram a distinção entre 'agrícola' e 'não-agrícola' que existia apenas entre aqueles com ou sem hukou local. Governos locais também ganharam poder para decidir os critérios para conceder o hukou local (denominado 'condições de entrada'), que se tornou o principal mecanismo de regulação da migração. Em suma, enquanto anteriormente eram utilizados dois procedimentos para a migração hukou, em alguns locais foi simplificado para apenas um procedimento, como foi o caso em Shenzhen, Ghangzhou e alguns distritos de Pequim (CHAN, 2009).

Um exame mais detalhado do programa que elimina a distinção entre 'agrícola' e 'nãoagrícola' da população local demonstra que não é somente uma extensão de benefícios já existentes para outros cidadãos. Na maioria dos casos, a situação é bem mais complexa: a população rural local recebe o novo hukou urbano (com alguns benefícios) em troca de perder permanentemente o direito de uso da terra, um ativo que poderia render grandes benefícios financeiros para o governo local em uma região urbanizada. Esta 'equalização' é segundo Chan (2009) uma forma indireta de reapropriação.

As 'condições de entrada' para adquirir o hukou local são elevadas. Apenas um pequeno grupo pode se qualificar (como milionários capazes de comprar apartamentos de alto valor ou realizar grandes investimentos, ou aqueles com nível educacional elevado ou excelente qualificação profissional), o que, de certa forma, imita as medidas e princípios utilizados por governos de outros países em seus programas de 'imigração de negócios' ou 'imigração de talentos'. Algumas cidades aplicaram o programa de permitir pessoas qualificadas a adquirir o hukou urbano, mas estas medidas foram muito limitadas em escopo e foram descontinuadas após algum tempo.

Isto sugere que as novas iniciativas tiveram pouca relevância para a grande maioria dos trabalhadores rurais migrantes 'não-locais', ou seja, ainda não houve mudança significativa no sistema hukou. Nota-se, porém, que a única modificação relevante no período pós-1984, foi remover os obstáculos para mobilidade geográfica fora da arquitetura de conversão hukou. Isto permitiu que camponeses pudessem receber um rendimento extra para trabalhar nas cidades. Com isto, o aumento do número de não-hukou migrantes (população flutuante) tornou-se a grande marca da China nos últimos trinta anos. 


\section{O impacto do sistema hukou no crescimento econômico chinês}

O sistema hukou tem sido um dos maiores responsáveis pelo crescimento econômico, controlando e regulando a população e o fluxo de trabalho. O sistema hukou é uma herança do sistema de economia centralmente planejada. Sem este sistema, apesar de outros grandes esforços, a China não teria sido capaz de atingir o objetivo de uma rápida industrialização em tão pouco tempo (CHAN, 2009). Particularmente, quando a China implementou sua política industrial exportadora em meados dos anos oitenta, a utilização de trabalhadores migrantes rurais nas cidades para emprego na indústria tornou-se uma importante estratégia de desenvolvimento econômico do período pós-Mao.

A falta do registro de hukou local para os trabalhadores rurais impediu, a eles, o acesso a diversos serviços sociais básicos. Dessa forma, combinado com outras condições desfavoráveis como a falta de acesso ao suporte e informação legal, foi criada, de acordo com Alexander e Chan (2004), uma classe numerosa de trabalhadores super-explorados de extrema mobilidade e flexibilidade. Isto pode ser percebido na recente crise global de 2008 que atingiu seriamente o setor exportador da China, onde aproximadamente 20 milhões de trabalhadores migrantes ficaram desempregados. Acredita-se que estes foram os grandes responsáveis pelo imenso fluxo de pessoas no 'Movimento de Primavera' de $2009^{1}$.

Desta forma de acordo com Chan e Ross (2003), o 'preço China' tem sido, basicamente, justificado pelo seu reduzido custo de mão de obra onde seus trabalhadores recebem baixos salários, se comparados aos pagos em outros países em desenvolvimento. O custo do trabalhador migrante, segundo Lu, Shukai e Nansheng (2009), foi estimado em 44\% do custo do trabalhador urbano regular em 1995 e esta estimativa não considera os inúmeros subsídios concedidos aos residentes portadores do hokou urbano.

Outros estudiosos como Knight e Song (1999) mostraram em análises empíricas que a ausência do status de hukou local resulta em salários significativamente menores comparados aos dos trabalhadores portadores do mesmo. Há casos em que além de baixos salários, os trabalhadores migrantes não recebem o pagamento em dia, atrasando em alguns meses e até anos, não sendo, muitas vezes, efetivamente pagos. A utilização do trabalhador migrante tem servido para alavancar a estratégia de crescimento econômico da China como um país produtor de baixo custo. A China continua a utilizar trabalhadores provenientes da zona rural para exercer atividades industriais e comerciais em áreas urbanas e em suas zonas de exportação, pagando, porém salários equivalentes aos pagos na área rural.

De acordo com Liang (1999), a cidade de Shenzhen é um grande exemplo da implementação da nova estratégia de industrialização e reconhecida como o milagre da reforma econômica da China. Não por coincidência, Shenzhen é a cidade com o maior número de trabalhadores migrantes. Conforme dados oficiais, sua população que em 1990 era de 1,2 milhão cresceu para 10,3 milhão em 2010. Desta população, a maior parte é composta de migrantes que não possuem o hukou local e são excluídos dos benefícios concedidos pelo governo. Esta prática é encontrada em diversas partes do Delta do Rio das Pérolas e outras regiões da China. Segundo Chan, (2009) os governos de Guangdong (província) e de Shenzhen (cidade) 
reconhecem que sem o trabalhador migrante rural não poderiam ter atingido o rápido crescimento econômico dos últimos trinta anos. 


\section{Controle da natalidade e a política do filho único}

Em 1949, quando a República Popular da China foi estabelecida, o país possuía uma população aproximada de 540 milhões de pessoas e o governo argumentava que precisava de uma nação populosa para reforçar sua força política e prover trabalho para o desenvolvimento econômico. Em 1953, com o primeiro censo nacional, a China contabilizou 583 milhões de habitantes e uma taxa de fertilidade superior a seis crianças por mulher (WORLD BANK, 2011). Em meados da década de cinquenta, temendo que o crescimento populacional excessivo prejudicasse o desenvolvimento econômico e com intenção de dar uma educação em massa adequada, oportunidade de trabalho, e melhorar as condições de vida da população, o governo segundo Riley (2004) reverteu sua posição inicial e procurou implementar alguma forma de planejamento familiar.

Tien et al (1992) esclarecem que a primeira campanha de controle de natalidade iniciou nos anos cinquenta dando enfoque ao bem estar da mãe e do bebê. Já, de acordo com Riley (2004), a segunda campanha iniciada em 1962 que durou até o início da Revolução Cultural de 1966, buscava um planejamento familiar na área rural por meio de uma forma educativa, tentando ensinar as famílias rurais sobre os benefícios de ter uma família menor. A terceira campanha ('wan, xi, shao' ou 'tarde, longo e pouco') iniciada em 1971, enfatizou casamentos tardios e maiores intervalos entre os nascimentos. Esta campanha teve um impacto muito mais amplo que os esforços anteriores, diminuindo pela metade a taxa de fertilidade, que era de 5,5, para 2,7 nascimentos por mulher (WORLD BANK, 2011).

No final da década de setenta, o governo chinês estabeleceu a meta do país em atingir a prosperidade até o término do Século XX. Porém, conforme Huang (1982), com a população próxima a atingir a marca de 1 bilhão de pessoas, o objetivo de buscar a prosperidade ficava comprometido. Isto foi demonstrado com os estudos de projeção populacional do cientista Song Jian que influenciou de maneira significativa o governo chinês em estabelecer uma política populacional mais severa (GREENHALGH, 2005). O incremento populacional chinês desde 1949 foi três vezes superior ao dos Estados Unidos e seis vezes ao do Japão.

Song Jian mostrou que o controle populacional não era apenas uma questão de desenvolvimento econômico, mas também afetaria a disponibilidade de recursos, traria problemas ambientais e poderia comprometer a própria sobrevivência humana (FENG, 2005). Nesse contexto, para Greenhalgh (2005), uma taxa de fertilidade entre 1,0 e 1,5 seria o nível mais adequado para rapidamente se estabilizar e evitar uma explosão populacional.

Em 1979, o governo chinês implantou o programa de natalidade do filho único, que consistia inicialmente em buscar um maior controle da natalidade ao estabelecer que cada casal tivesse apenas um filho, mediante aprovação oficial antes da geração de seu descendente. Casais com apenas uma criança teriam certa preferência com relação à educação, saúde, moradia e trabalho (RILEY, 2004). Feng (2005) menciona que esta política foi o maior e mais extremo experimento social em controlar o crescimento populacional via intervenção governamental em reprodução humana na história mundial. 
No início da implementação do programa, regras anticoncepcionais eram restritivas e incentivavam as mulheres a realizar esterilização após dois nascimentos (TIEN et al., 1992) ou mesmo praticar o aborto (EBENSTEIN, 2010). Depois de resistências principalmente da zona rural, o governo fez alguns ajustes permitindo as famílias que trabalhavam na área agrícola a ter mais de um filho. Muitas províncias também começaram a permitir casais a ter dois filhos quando a esposa fosse filha única.

Outras exceções também foram concedidas para casais que tinham apenas crianças do sexo feminino, para pessoas de grupos minoritários étnicos ou indivíduos que moravam em áreas pobres. Mesmo com estas concessões, aproximadamente dois terços dos casais chineses estão sob a jurisdição da política do filho único (FENG, 2005). O resultado desta política de controle populacional implementada no final da década de setenta, fez com que a taxa de fertilidade diminuísse de 2,7 para 1,7 crianças por casal e a taxa de natalidade reduzisse de 21 para 12 nascimentos para cada 1.000 habitantes em 2009 (WORLD BANK, 2011).

Com a política de filho único houve um desequilíbrio na distribuição populacional por sexo no país, com uma proporção muito maior de homens, ocorrendo o problema de 'missing girls' ou desaparecimento de meninas (JOHANSSON; NYGREN, 1991; COALE; BANISTER, 1994; EBENSTEIN; SHARYGIN, 2009; EBENSTEIN, 2010). A preferência por bebê do sexo masculino é relacionada com o papel social e econômico que os homens desempenham na família chinesa. Os homens traçam a linhagem familiar e são responsáveis por cuidar de seus pais na velhice. O casamento mostra claramente este papel. Quando a filha se casa, esta deixa sua família para morar e ajudar a família do esposo. Desta forma, um casal que possui apenas criança do sexo feminino, poderá no futuro envelhecer sem auxílio financeiro e pessoal.

Outras explicações são dadas para o fenômeno 'missing girls' tais como o excesso de mortes de bebês do sexo feminino via infanticídio, negligência ou abandono. Segundo Zeng et al (1993) era também frequente a adoção de crianças do sexo feminino, o seu não registro de nascimento e abortos seletivos. Este último é considerado uma das causas principais para a distorção da distribuição por gênero, principalmente com o uso do pré-natal na determinação do sexo e subsequente decisão de abortar seletivamente (GU; XU, 1994).

Outra consequência da política do filho único está associada ao aumento da expectativa de vida e envelhecimento da população com um número menor de pessoas jovens para dar suporte ao crescente número de idosos no país. Estima-se que em 2050, $27 \%$ da população estará com idade acima de 60 anos, que corresponde a quase três vezes a proporção de idosos em 2000. Com isso, o filho único terá que arcar com o cuidado dos familiares idosos, surgindo o fenômeno '4-2-1', em que o jovem (filho único) tem que ser responsável pelos avós (4) e pais (2) (ZHANG; GOZA, 2006; MIAN, 2007).

A questão de ter apenas um filho também pode estar relacionada a algumas outras questões. Por um lado, os pais podem dar maior devoção e recursos para criar apenas um filho (HESKETH; ZHU, 1997). Por outro, existem problemas associados à questão psicológica e social de ter apenas um filho, criando a geração denominada de 'pequeno imperador' (CHEN, 1994). Segundo Festini e Marino (2004), esta geração poderá ser mais egoísta e o centro das atenções, pode receber excesso de proteção dos familiares, pode ser tornar insegura pela 
excessiva pressão e expectativa paterna, ter dificuldades em se avaliar com relação aos seus companheiros e assumir responsabilidades. Também será uma geração sem irmãos, e também sem tios ou tias.

Há também as implicações ligadas ao mercado de trabalho. Um exemplo é a disputa de profissionais qualificados por multinacionais e empresas domésticas, pois já se menciona a escassez de mão de obra especializada. Assim, as empresas disputam para atrair ou manter pessoal qualificado, o que acarreta aumentos salariais, bônus e melhores pacotes de benefícios. Para Granby (2011), a escassez também afeta as atividades que demandam baixa qualificação, já que menos trabalhadores chineses estão optando por trabalho mais braçal e de menor remuneração. 


\section{Paradoxo da escassez e do excedente de mão de obra na China}

É comum se estabelecer uma relação entre o baixo custo de mão de obra na China, simplesmente, com o excedente da população, ou seja, possuir mais de um bilhão de habitantes parece refletir em uma oferta quase infinita de trabalho para o mundo. Recentemente, uma série de eventos tem despertado interesse internacional sobre a atual situação da oferta de trabalho na China. Desde os primeiros meses de 2010, algumas fábricas chinesas da área litorânea vêm apresentando dificuldades em recrutar e contratar trabalhadores. Segundo Chan (2010a), em julho de 2010, a mídia divulgou que fábricas em Guangdong contrataram trabalhadores ilegais do Vietnã e de outros lugares.

Isto surpreende, pois apenas um ano antes a situação era completamente oposta, ou seja, cerca de 23 milhões de trabalhadores migrantes eram demitidos devido à crise mundial (CAI; CHAN, 2009; CAI; WANG, 2010; WANG, 2010). Parece improvável que ocorra a escassez de mão de obra no momento em que a população economicamente ativa da China, a maior do mundo, atingiu seu ápice com mais de 800 milhões de pessoas em 2010, e está projetado seguir nova expansão até 2015 (CAI, 2008; KROEBER, 2010). A escassez e o excedente de mão de obra na China parecem ser incompatíveis e paradoxais.

A carência de mão de obra, primeiramente, ocorreu nas áreas litorâneas e em seguida no interior do país, podendo ser atribuída aos setores emergentes e ao rápido crescimento econômico (WU, 2007). Zhao (2002) sugere que as barreiras artificiais como o sistema hukou acarretaram um efeito negativo significativo na migração do trabalhador rural. Entretanto, a mídia apresentou recentemente reportagens sobre esta escassez de trabalho e o fim do excedente da oferta de trabalho na China, mostrando que as empresas multinacionais têm dificuldades em manter e recrutar pessoas com qualificação (DEMICK; PIERSON, 2010; GRANBY, 2011).

Pesquisadores como Chen e Hamori (2010), que levaram em consideração tanto a oferta como a demanda de trabalho, mostraram que as causas do excedente de mão de obra na área rural e a carência severa de trabalhadores migrantes coexistem desde 2003. Suas análises revelam claramente que a baixa escolaridade nas áreas rurais tem um efeito negativo na escolha de emprego para os migrantes. Isto demonstra que a maioria dos migrantes é empregada em postos de trabalho de baixa qualificação, e apenas uma pequena minoria consegue a residência urbana e um posicionamento melhor no mercado de trabalho.

Utilizando um modelo de estimativa estatística denominado probit, esses pesquisadores confirmam a importância do nível educacional, pois a chance de conseguir um emprego permanente cresce à medida que aumenta o nível educacional do trabalhador migrante. Assim, sugerem que devem ser implementadas políticas com objetivo de aumentar o nível educacional dos trabalhadores rurais e devem ser removidas as barreiras artificiais, para aumentar a inclinação dos trabalhadores rurais a migrarem. Outros autores argumentam que a China vem alcançando o 'Lewis Turning Point' (ZHANG et al., 2010), que será exposto no próximo tópico. 


\section{Debate sobre o modelo 'Lewis Turning Point'}

O modelo 'Lewis Turning Point' (LTP) foi desenvolvido pelo ganhador do Prêmio Nobel Arthur Lewis (1954). Consiste em um marco conceitual para avaliar o sucesso de uma economia em desenvolvimento e para explicar as formas de como os resultados do desenvolvimento econômico são difundidos. Em um mercado competitivo, somente quando a economia passa de um primeiro estágio clássico de processo de desenvolvimento (excedente de mão de obra) e entra no segundo estágio neoclássico (escassez de oferta de trabalho), é que geralmente a renda real começa a aumentar.

Até este ponto, os benefícios do crescimento econômico podem aumentar na forma de absorção do excedente da oferta de mão de obra. Após este ponto o que se espera é a redução da desigualdade de renda, tentando acabar assim com a enorme lacuna econômica e social existente entre a área rural e urbana em um futuro próximo (KNIGHT et al., 2010). Obviamente, esta mudança refletirá não apenas na China, mas também em outros países, já que a nação asiática é o maior exportador mundial (GARNAUT, 2010; HUANG; JIANG, 2010), além de grande importador.

O processo segundo o qual uma economia se move do estágio clássico para o neoclássico é ilustrado pela experiência do Japão (décadas de 50-60), e da Coreia do Sul (décadas de 6070). Quando as reformas iniciaram, não havia dúvidas de que a China era um exemplo extremo de uma economia com excedente de mão de obra, tanto rural como urbana. Durante o período de reforma, o país atingiu um rápido crescimento econômico com uma média superior a 9\% ao ano durante três décadas (1978-2008). No mesmo período, a força de trabalho aumentou 380 milhões, um crescimento de $90 \%$ equivalente a média de $2,3 \%$ por ano (KNIGHT et al., 2010).

Vários pesquisadores têm argumentado que a China atingiu o LTP, baseados parcialmente na evidência do aumento de salário recente dos trabalhadores migrantes (CAI et al., 2007; PARK et al., 2007; ZHANG et al., 2010). Examinando a transição demográfica, há estimativas que mostram que a força de trabalho da China começará a diminuir por volta de 2020, e esta desaceleração projetada é um sinal que o LTP é iminente (CAI, 2008; KROEBER, 2010). Outros pesquisadores (KWAN, 2009; MINAMI; MA, 2009; YAO, 2010) têm argumentado que o alcance do LTP ainda é prematuro, visto que existe um excedente (apesar de estar diminuindo) e não uma escassez de mão de obra rural no país.

Knight et al. (2010) tentaram achar uma resposta para este debate baseados em dados obtidos por um levantamento conduzido pela China Household Income Project (CHIP) nos anos de 2003 e 2008. O resultado da análise evidencia a existência simultânea de excedente de mão de obra na área rural e aumento do salário dos trabalhadores migrantes rurais na área urbana. Estes dois fenômenos seriam, em tese, inconsistentes com a hipótese do modelo de Lewis para o mercado de trabalho. Porém, é válida a interpretação de que existe, de fato, uma segmentação do mercado de trabalho chinês, com a restrição à migração do trabalho ruralurbano. 
Essa restrição institucional criou dificuldades para os migrantes residirem nas áreas urbanas (com um emprego bom e seguro, moradia, e acesso aos serviços públicos) e trazerem suas famílias para a cidade. Restringe-se também muitos trabalhadores rurais a deixarem suas vilas por um longo período. Embora haja evidências de que o mercado chinês para trabalhadores migrantes tenha se tornado mais integrado, é possível que os dois fenômenos que provocam inflexibilidade no mercado de trabalho ainda continuem a existir por muitos anos. Em outras palavras, não se alcançará necessariamente um LTP em um país gigantesco e regulamentado, como é a China. Haverá um longo estágio de mudança que resultará não somente da heterogeneidade do setor rural, mas também da resistência das instituições do mercado de trabalho da China à mudança.

A projeção das tendências realizadas por Knight et al. (2010) indica que o número de migrantes rural-urbano crescerá rapidamente. Em 2020, os migrantes constituirão por volta de dois terços do emprego urbano e a força de trabalho rural residual será um terço menor que em 2005. Porém, antes daquela data é provável que haja uma resposta endógena tanto do mercado como do governo. No mercado de trabalho, há expectativa do salário das pessoas menos qualificadas crescer, enquanto que o governo deverá se preocupar com as políticas de aposentadoria, controle de natalidade e urbanização.

A escassez de trabalho não qualificado é provavelmente a mais poderosa força de mercado para reduzir a desigualdade de renda na China (que aumentou significativamente durante o período de reforma econômica). O crescimento acelerado da renda do trabalho não qualificado dependerá de uma mudança de estratégia de desenvolvimento na direção de atividades econômicas voltadas para uma maior qualificação e intensidade tecnológica, que necessita de um planejamento de longo prazo e investimento em capital humano. Há ainda pouca evidência de que esta mudança na economia já esteja produzindo resultados, apesar da expansão da educação superior desde 1998. Contudo, devido ao contínuo crescimento acelerado no emprego urbano e rápida transição demográfica, é provável que isto ocorra na década em curso. 


\section{Considerações finais}

As altas taxas de crescimento econômico chinês nestes últimos trinta anos foram em grande parte sustentada pela abundante oferta da força de trabalho no país. "A China é um caso único. É um país muito populoso e com suficiente mão de obra que auxiliou no desenvolvimento do país", relatado durante a entrevista realizada em janeiro/2011 com o presidente de uma subsidiária de uma empresa chinesa do setor metal mecânico.

Particularmente, a grande disponibilidade de trabalhadores migrantes rurais, embora inicialmente não qualificados para o setor industrial, bem como a existência do sistema hukou, serviram para suprir as necessidades das empresas chinesas a um custo relativamente baixo comparado ao mercado internacional. Isto repercutiu em bons níveis de produtividade associados a baixos salários, beneficiando, nesse primeiro momento, a competitividade em produtos intensivos em trabalho. Possibilitou ainda o surgimento do chamado "preços chineses" onde houve a drástica redução de custos e preços de certos tipos de manufaturas com impacto mundial (CASTRO, 2007). Este foi o primeiro momento da rápida industrialização e urbanização do país.

Em um segundo momento, particularmente a partir do início do século XXI, observou-se grande reorganização da mão de obra que, ainda controlada quanto a sua oferta interna setorial e geograficamente pelo governo, passou a reivindicar melhores condições de trabalho - o que vem refletindo nos níveis salariais. O alcance do Lewis Turning Point e o impacto da política do filho único não foram diretamente mencionados durante as entrevistas com executivos chineses, mas relatados de forma indireta e há sinais claros que a mão de obra não especializada vem conseguindo um aumento considerável no nível salarial. Contudo, este aumento não ocorre a ponto de corroer a produtividade. "Há uma redução de oferta de mão de obra na região e houve um aumento considerável de nossos custos com a folha de pagamento. Mesmo assim, no mercado internacional conseguimos competir oferecendo uma política de preço 10\% menor que os concorrentes com qualidade equivalente", menciona o executivo de uma empresa chinesa especializada em produtos biomédicos.

Ademais, a qualificação da mão de obra levada a cabo pelo governo nesse segundo período proporciona, a custo relativamente baixo, mão de obra qualificada, que vem propiciando ganhos de competitividade em indústrias intensivas em tecnologia. "Nossa empresa possui $40 \%$ de quadro de profissionais em $P \& D$. Destes $97 \%$ possuem graduação em universidades, e aqueles que possuem nível de pós-graduação $70 \%$ são mestres e $30 \%$ são doutores ou possuem pós-doutorado. Investimos mais de $10 \%$ de nossas receitas em $P \& D$. Nossa remuneração chega a $70 \%$ do maior salário pago neste setor na China”, mencionado durante a entrevista com o vice-presidente de uma empresa de alta-tecnologia no setor de telecomunicações instalada na região de Shenzen.

Observa-se um crescente nível de qualificação dos chineses como resultado da política de educação em massa. O país possui o maior número de graduados em universidades principalmente de engenheiros que representam um terço dos estudantes universitários. 
Porém, nota-se que as empresas vêm apresentando dificuldades para contratar talentos, já que a quantidade está sendo atendida, mas não com a qualidade esperada. "Apesar de existir um número crescente de profissionais, estamos sentindo dificuldades em contratar pessoas mais talentosas em nosso segmento. Tentamos recrutar estes talentos nos EUA com estudantes chineses de MBA, ou chineses que residem em Hong Kong ou Cingapura”, relata o diretor internacional de RH de uma empresa chinesa líder do setor de aparelhos médicos.

Debates do Lewis Turning Point, o efeito resultante da política do filho único, o envelhecimento da população, as reformas no sistema hukou, aumento considerável da renda do trabalhador, a mobilização coletiva de trabalhadores, a disputa por talentos entre outros oferecem ainda grandes desafios para as empresas chinesas nos próximos anos. Mudanças já foram realizadas nestas últimas três décadas para possibilitar à China a alcançar um alto nível de crescimento econômico. O grande desafio é transformar o país não apenas competitivo em mão de obra intensiva, mas também produtor de inovação e tecnologia. As entrevistas com executivos chineses mostraram que algumas empresas já estão caminhando neste sentido e atingindo resultados surpreendentes em pouco tempo.

\section{Notas}

${ }^{1}$ Movimento de Primavera é um evento anual que mobiliza milhões de chineses a visitarem seus familiares e parentes para celebrar o Ano Novo Lunar. 


\section{Referências}

ALEXANDER, P.; CHAN, A. Does China have an apartheid pass system? Journal of Ethnic and Migration Studies, v. 30, n. 4, p. 609-629, 2004.

CAI, F. Approaching a triumphal span: how far is China towards it Lewisian turning point? WIDER Research Paper. 2008.

CAI, F.; CHAN, K. W. The global economic crisis and unemployment in China. Eurasian Geography and Economics, v. 50, n. 5, p. 513-531, 2009.

CAI, F.; WANG, M. Growth and structural changes in employment in transition China. Journal of Comparative Economics, v. 38, n. 1, p. 71-81, 2010.

CAI, F. et al. Regional labour market integration since China's WTO entry: evidence from household-level data. In: GARNAUT, R.; SONG, L. (Ed.). China: linking markets for growth. Canberra: Asia Pacific Press, 2007. p. 133-150.

CASTRO, A.B. No espelho da China. Rio de Janeiro. Mimeo. 2007.

CHAN, A.; ROSS, R. J. S. Racing to the bottom: industrial trade without a social clause. Third World Quarterly, v. 24, n. 6, p. 1011-1028, 2003.

CHAN, K. W. Economic growth strategy and urbanization policies in China, 1949-82. International Journal of Urban and Regional Research, v. 16, n. 2, p. 275-305, 1992.

CHAN, K. W. Cities with invisible walls: reinterpreting brbanization in Post-1949 China. New York: Oxford University Press, 1994.

CHAN, K.W. Misconceptions and complexities in the study of China's cities: definitions, statistics, and implications. Eurasian Geography and Economics, v.48, n.4, p.383-412, 2007.

CHAN, K. W. Internal labour migration in China: trends, geographical distribution and policies. In: Proceedings of the United Nations Expert Group Meeting on Population Distribution, Urbanization, Internal Migration and Development. 2008.

CHAN, K. W. The Chinese hukou system at 50. Eurasian Geography and Economics, v. 50, n. 2, p. 197-221, 2009.

CHAN, K. W. A China paradox: migrant labor shortage amidst rural labor supply abundance. Eurasian Geography and Economics, v. 51, n. 4, p. 513-530, 2010a.

CHAN, K. W. China, internal migration. University of Washington Working Paper, 2010b.

CHAN, K. W.; BUCKINGHAM, W. Is China abolishing the hukou system? The China Quarterly, v. 195, p. 582-606, 2008.

CHAN, K. W.; ZHANG, L. The hukou system and rural urban migration: processes and changes. The China Quarterly, v. 160, n. 818-855, 1999.

CHEN, B. A little emperor: one-child family. Integration, n. 39, p. 27, 1994.

CHEN, G.; HAMORI, S. Solution to the dilemma of the migrant labor shortage and the rural labor surplus in China. China \& World Economy, v. 17, n. 4, p. 53-71, 2010.

CHENG, T.; SELDEN, M. The origin and social consequences of China's hukou system. The China Quarterly, v. 139, p. 644-668, 1994. 
COALE, A.; BANISTER, J. Five decades of missing females in China. Demography, v. 31, n. 3, p. 459-486, 1994.

DEMICK, B.; PIERSON, D. People, people everywhere in China, and not enough to work. Los Angeles Times, 2010.

DUTTON, M. R. Policing and punishment in China: from patriarchy to "the People". New York: Cambridge University Press, 1992.

EBENSTEIN, A. The "Missing Girls" of China and the unintended consequences of the one child policy. Journal of Human Resources, v. 45, n. 1, p. 87-115, 2010.

EBENSTEIN, A.; SHARYGIN, E. J. The consequences of the "Missing Girls" of China. The World Bank Economic Review, v. 23, n. 3, p. 399-425, 2009.

FENG, W. Can China afford to continue its one-child policy ? Analysis from the East-West Center - Asian Pacific Issue, v. 77, p. 1-12, 2005.

FESTINI, F.; MARINO, M. Twenty five years of the one child family policy in China. Journal of Epidemiology \& Community Health, v. 58, p. 358-360, 2004.

GARNAUT, R. "Macro-economic implications of the turning point." Palestra ministrada em "International Workshop on Debating the Lewis Turning Point in China.". Beijing 2010.

GOLDSTEIN, S.; GOLDSTEIN, A. Permanent and temporary migration differentials in China, Honolulu, Hawaii: East-West Center, 1991.

GRANBY, J. Labour shortages lead to re-think of one-child policy. Disponível em: $<$ http://www.dailyfx.com/>. Acesso em 20 de março de 2011.

GREENHALGH, S. Missile science, population science: the origins of China's one-child policy. The China Quarterly, v. 182, p. 253-276, 2005.

GU, B.; XU, Y. A Comprehensive discussion of the birth gender ratio in China. Chinese Journal of Population Science, v. 6, n. 4, p. 417-431, 1994.

HESKETH, T.; ZHU, W. X. The one child family policy: the good, the bad and the ugly. BMJ, v. 314, p. 1685-1687, 1997.

HUANG, L. J. Planned fertility of one-couple one-child policy in the People's Republic of China. Journal of Marriage and Family v. 44, n. 3, p. 775-784, 1982.

HUANG, Y.; JIANG, T. What does the Lewis Turning Point mean for China? China Center for Economic Research, Peking University Working Paper Series. Beijing. 2010.

JOHANSSON, S.; NYGREN, O. The missing girls of China: a new demographic account. Population and Development Review, v. 17, n. 1, p. 35-51, 1991.

KNIGHT, J. et al. The puzzle of migrant labour shortage and rural labour surplus in China, University of Oxford Department of Economics Working Paper Series. Oxford, U.K.: University of Oxford, 2010.

KNIGHT, J.; SONG, L. The rural-urban divide: economic disparities and interactions in China. New York: Oxford University Press, 1999.

KROEBER, A. The end of surplus labor. China Economic Quarterly, v. 1, p. 35-46, 2010.

KWAN, F. Agricultural labour and the incidence of surplus labour: experience from China during reform. Journal of Chineses Economic and Business Studies, v.7, n.3, p.341-361, 2009. 
LEWIS, W. A. Economic development with unlimited supplies of labour. The Manchester School, v. 22, p. 139-192, 1954.

LIANG, Z. Foreign investment, economic growth, and temporary migration: the case of Shenzhen Special Economic Zone. Development and Society, v. 28, n. 1, p. 115-137, 1999.

LU, M. et al. Zhongguo nongcun laodongli liudong de huigu yu zhanwang [Review and prospect of rural labor flows in China]. Disponível em: <http://www.chinaelections.org/ NewsInfo.asp?NewsID=76500 . Acesso em: 24 de março de 2011. 2009.

MALLEE, H. China's Household registration system under reform. Development and Change, v. 26, n. 1, p. 1-29, 1995.

MATHEWS, M. The passport society: controlling movement in Russia and the USSR. Boulder, CO: Westview Press, 1993.

MIAN, M. 4-2-1 phenomenon: New partnership explores aging in China. Social Impact, n. Winter, p. 25-29, 2007.

MINAMI, R.; MA, X. The turning point of Chinese economy: compared with Japanese experience. Paper presented at "Adjustment to Global Financial Crisis" Conference in June 2009. 2009.

NATIONAL BUREAU OF STATISTICS. China Labour Statistical Yearbook 2010. Beijing. 2010

NAUGHTON, B. The Chinese economy. Cambridge, MA: MIT Press, 2007.

PARK, A. et al. Can China meet her employment challenges? Growing Pains: Tensions and Opportunity in China's Transformation, Stanford University, November 1-3, 2007.

RILEY, N. E. China's population new trends and challenges. Population Bulletin, v. 59, n. 2, p. 3-36, 2004.

ROBERTS, K. D. Female labor migrants to Shanghai: Temporary 'floaters' or settlers? International Migration Review, v. 36, n. 2, p. 492-519, 2002.

SOLINGER, D. J. Contesting citizenship in urban China: peasant migrants, the state, and the logic of the market. Berkeley: University of California Press, 1999.

TIEN, H.Y. et al. China's demographic dilemmas. Population Bulletin, v.47, n.1, p.2-44, 1992.

UNITED NATIONS DEVELOPMENT PROGRAMME. China human development report 1999: transition and the State. United Nations. Beijing. 1999

WANG, F. Boundaries of inequality: perceptions of distributive justice among urbanites, migrants, and peasants. In: Conference on Rethinking the Rural-Urban Cleavage in Contemporary China, Harvard University, Cambridge, MA. 2006.

WANG, F. L. Organizing through division and exclusion: China's hukou system. Stanford, CA: Stanford University Press, 2005.

WANG, M. Impact of the global economic crisis on China's migrant workers: a survey of 2,700 in 2009. Eurasian Geography and Economics, v. 51, n. 2, p. 218-235, 2010.

WORLD BANK. World Development Indicators. Washington D.C.: Disponível em: <http://data.worldbank.org/>. Acesso em 20 de março de 2011.

WU, H. X. Rural to urban migration in the People's Republic of China. The China Quarterly, v. 139, p. 669-698, 1994. 
WU, Y. Labor shortage continues and spreads. In: F.CAI; YANG, D. (Ed.). Green Book of Population and Labor. Beijing: Social Sciences Academic Press, 2007. p. 63-94.

YANG, D.; FANG, C. The political economy of China's rural-urban divide. In: HOPE, N. et al (Ed.). How far across the river? Chinese policy reform at the millennium. Stanford, CA: Stanford University Press, 2003. p. 389-416.

YAO, Y. The Lewisian Turning Point has not yet arrived. The Economist, 2010.

ZASLAVSKY, V.; LURYI, Y. The passport system in the USSR and changes in Soviet society. Soviet Union, v. 6, n. 2, p. 137-153, 1979.

ZENG, Y. et al. Causes and implications of the recent increase in the peported sex ratio in China. Population and Development Review, v. 19, n. 2, p. 283-302, 1993.

ZHANG, X. et al. China has Reached the Lewis Turning Point, Discussion Paper 977. International Food and Policy Research Institute. Washington D.C. 2010.

ZHANG, Y.; GOZA, F. W. Who will care for the elderly in China? a review of the problems caused by China's one-child policy and their potential solutions. Journal of Aging Studies, v. 20, p. 151-164, 2006.

ZHAO, Y. Causes and consequences of return migration: recent evidence from China. Journal of Comparative Economics, v. 30, n. 2, p. 376-394, 2002.

ZHU, L. The hukou system of the People's Republic of China: a critical appraisal under International Standards of Internal Movement and Residence. Chinese Journal of International Law, v. 2, n. 2, p. 519-565, 2003. 